\title{
Touching is Worlding: From Caring Hands to World- Making Dances in Multispecies Childhoods
}

\author{
Tuure Tammi and Riikka Hohti
}

\begin{abstract}
Tuure Tammi, PhD, formerly an elementary school teacher, is a postdoctoral research fellow at the University of Oulu in the AniMate research group. His research is situated at the intersection of childhood studies and education with a focus on multispecies relations. His current research interests include matters of care in child-animal relations, the role of microbes in (environmental) education, and toxic embodiment in childhood. Tammi's research article on participation and posthumanism that was co-written with Riikka Hohti and published in the Finnish journal of historical and societal educational research Kasvatus \& Aika was awarded Article of the Year in 2018. Email: tuure.tammi@oulu.fi

Riikka Hohti conducts research on child-animal relations, and materiality, digitality, and temporality in education. She has worked as a lecturer in the Faculty of Education, University of Helsinki, as a postdoctoral researcher in the AniMate research group, University of Oulu, and as a postdoctoral research fellow in the Educational and Social Research Institute in Manchester Metropolitan University. Her current project at the University of Helsinki focuses on more-than-human education and care. Hohti has published peerreviewed articles in journals such as Childhood, Kasvatus \& Aika, and Qualitative Studies in Education, and she is coauthor of the book Lasten ja eläinten suhteet: monilajista yhteiseloa (Child-Animal Relations; forthcoming in 2020). Email: riikka.hohti@helsinki.fi
\end{abstract}

In this article we analyze the phenomenon of touch to discuss care and knowing within child-animal relations. The empirical part was conducted as a multispecies ethnography in a comprehensive school with an educational zoo built in a huge greenhouse. Storytelling, Despret's idea of "versions," and insights drawn from dance are used to take a close look at touching events between the research participants. From observations of caring hands and the materialdiscursive dimensions involved in stroking, the article moves on to consider ways of knowing and not-knowing that intertwine and are produced in touch. Finally, touch is discussed as a complex worlding dance that always takes more than two.

Key words: touch; child-animal relations; care; multispecies ethnography; dance
It is time for the animal club. Primary school students rush inside the greenhouse. One of the kids, Jaana, puts her hand in the terrarium in which Fudge and Marshmallow live. She holds some seeds on her palm to make the gerbils interested. Fudge and Marshmallow come to sniff the hand and to climb on it. Jaana attempts to grab the gerbils, misses, then tries again. After a while she holds Fudge in her hands and smiles. "Is it soft?" I ask. "Quite, but it has sharp nails." There is something mesmerizing in the dance the gerbil and the hands make together. (storytelling fieldnotes)

This article examines the phenomenon of touch to illustrate child-animal relations and care within encounters between young humans and other-thanhuman animals. These encounters take place within a multispecies educational zoo, built in a big greenhouse in the atrium of a Finnish comprehensive school. In the greenhouse, a caretaking practice has been established that involves training volunteer students as responsible carers for their respective animals. Through looking closely at situations in which bodies touch each other, our analysis aims at addressing the embodied, lived, and fleshy dimensions of child-animal relations while troubling anthropocentric habits of thinking about care, touch, and research.

A growing amount of childhood scholarship examines childhoods as relational, material, and more than human, thus challenging the divided notions of nature/culture and human/animal (see, e.g., childhoodnature 
scholarship, Cutter-McKenzie-Knowles et al., 2018; Taylor \& Pacini-Ketchabaw, 2018). We have previously analyzed engagements between children and other animals in the greenhouse, theorizing childhood, childanimal relations, and care beyond essentializing "natural" and innocent imaginaries (Hohti \& Tammi, 2019). Following the premise of human nature as an interspecies relationship presented by Anna Tsing (2012) and Richard Grusin (2015), we presented the concept of multispecies childhood that entails defining human childhood through connections and interdependencies among species rather than through the distinction between humans and other animals (Hohti \& Tammi, 2019). In this paper we build on this empirical and conceptual work by focusing on multispecies bodies and touch. What a body can do and become is a central question in the current body and affect theory (Blackman, 2012; Despret, 2016; Manning, 2007, 2014), one that needs to be thought along with the complexities of lived bodily connections. In the words of feminist scholar Maria Puig de la Bellacasa (2017), dealing with noninnocent care requires hands-on "impure involvement" in the world.

Our analysis draws on Spinozian-Deleuzian conceptualizations of the body as processual, emerging from relationality, always in movement or in a "becoming" state, and more than human (Blackman, 2012; Manning, 2007). Our approach to the interspecies encounters between humans and other animals in the greenhouse is informed by the more-than-human ethics of care presented by Puig de la Bellacasa (2017), who theorizes care as consisting of three necessarily coexisting dimensions: the material (embodied) dimension of labour, the affective dimension, and the ethico-political dimension. The tensions between these three layers give her concept of care its critical edge: for her, care is always noninnocent. Crucially, these theories urge us to move from asking what a body is, to what it does and can do in situated practices - to an emphasis on the capacities of the body to affect and to become affected (Blackman, 2012; Despret, 2014; Manning, 2007, 2014).

Puig de la Bellacasa (2017) notes that there is a specific promise in touch about embodied modes of thinking and knowing, modes that would be "in touch" with materiality and thus not restricted to the otherwise dominant visual and linguistic forms of meaning making. Similarly, this promise emerges in discourses regarding various dance forms, such as tango (Manning, 2007) and contact improvisation (Paxton, 1993; Turner, 2010). Moreover, touch is also a phenomenon deeply related to politics and ethics. For Karen Barad (2012), touching involves the inseparable dimensions of physicality, virtuality, affectivity, and emotions, and moreover, touch is a matter of ethics through her notion of response-ability:

Touching, sensing, is what matter does, or rather, what matter is: matter is condensations of responseability. Touching is a matter of response. Each of "us" is constituted in response-ability. Each of "us" is constituted as responsible for the other, as the other. (Barad, 2012, p. 215)

Thus, knowing does not come from observing the world from a distance but from engagement with(in) it. Donna Haraway (2008) speaks about "critters" being involved in co-making of worlds in the processes of worlding, in which the question of who gets to live and die and how are at stake. World, in other words, is a verb or a gerund-worlding - an ongoing, more-than-human patterning through which species and their histories meet, and in which possibilities for invention, speculation, proposal, response are opened.

In the context of dance, specifically contact improvisation, touch has been regarded as potentially offering emancipatory possibilities through developing sensations and reflexes required for overcoming the restricted identifications available (Paxton, 1993; Turner, 2010). Importantly, in Steve Paxton's thinking (Paxton, 1993; Turner, 2010), improvisation moves toward new embodied modes of knowledge through orienting to that which is not yet known. This definition of improvisation emphasizes experimentation with the changing physical environment with appropriate placement and energy. 
In her theorization of touch through the metaphor of tango, Erin Manning (2007) points out how this dance is historically linked with national identity and cultural territory. However, these striations are continuously worked on by the dimension of not knowing involved in touching itself. Touch also necessarily affects and changes those involved in touching: After having touched or having been touched, we will literally never be the same again, even if the shift is sometimes microscopic, as we will discuss later. Touch is thus directed toward bodies and worlds yet to come, and its improvisational and responsive nature entails that the futures present in touch are never fully settled (Manning, 2007).

The relation between the possibility of embodied knowing and the stance of not knowing is the creative tension underpinning our exploration of touch in a multispecies context. In what follows, we will first describe the context of our research - the school greenhouse zoo-and our storytelling approach. Then we will take a closer look at the noninnocent practices of care among the human-animal relations in the greenhouse, specifically, selected touching events that involve gerbils and their young caretakers.

\section{Multispecies ethnography: Storying, touching, and being touched}

As part of a larger multispecies ethnographic research study, we spent five months (two days a week) with a group of young people, other animals, and school staff in a comprehensive school located in a suburb in southern Finland. The school houses one of the biggest educational greenhouses in the Nordic countries, complete with all the technology required to create a subtropical climate in the middle of the surrounding arctic environment. Established in the 1990s and first used as a rescue facility for homeless pets, the greenhouse has evolved into an unofficial educational zoo inhabited by both rescue animals and purchased ones and the offspring of both. The school is located in a disadvantaged, largely immigrant-background suburb, which is why the municipality directs the school some extra funding for the greenhouse, according to the so-called positive discrimination policy.

During the fieldwork period, the greenhouse inhabitants included some 40 bigger other-than-human animals such as turtles, rabbits, a parrot, a dove, cockatiels, a green iguana, a water dragon, a corn snake, mice, guinea pigs, gerbils, a rooster, and a hen. There were also smaller critters such as stick insects, ants, snails, mealworms, and flies. Plants included tropical fruit trees, jacarandas, hibiscuses, and more. Some other-than-human animals (such as the chicken and iguana) moved relatively freely around in the greenhouse, while most of them were in cages and terrariums. The birds mostly flew around and sat on beams close to the glass ceiling. The doors of the greenhouse were open to visitors, but an inner circle of some 20 students (aged 13-16) liked to spend most of their free time in the greenhouse. The young students appointed as caretakers of the other animals were mentored by two biology teachers, Armi and Taina. Some of the secondary school students also were leading socalled animal clubs, which were afternoon clubs for smaller children, aged 8-12. Often, no adults were present in the greenhouse. The young people spent time there on their own, taking full responsibility for feeding, cleaning, and other daily tasks related to maintaining the greenhouse and taking care of the other-than-human animals.

Our fieldwork made us engage with a stream of stories told by the children and the teachers about the inhabitants of the greenhouse. We quickly adopted storytelling as our primary way of writing fieldnotes and analysis, of which examples are shown in this article. In practice, during our field work, we would spend time in the greenhouse and listen, wander around, make contact with the other-than-human animals, and chat with people. We also took photos and videos. We would write down the stories we heard and go on working with the stories in an online document, allowing theoretical concepts and further empirical events to blend in in a rhizomatic manner. At the end of the field work period, the storied materials proved to be an engaging way 
to talk about our findings to the child research participants. In our storytelling-fieldnote writing we leaned on Haraway's (2016) ideas about the material-semiotic mutations of life, illustrated by her metaphor of "compost" and in her insistence that stories do things: "it matters what stories we tell to tell other stories with" (Haraway, 2016). Accordingly, while telling and retelling stories about touch, we also witnessed how these stories fuelled and encouraged further modes of touch in the greenhouse.

Äijä the iguana occupies a central place in the greenhouse. We usually find him standing (or sitting?) on a branch in his special glass-walled, extra-heated hut. Äijä is respected and acted upon with a certain cautiousness: already an eye contact with this slow, stiff reptile feels hypnotic. Tuure and I spend weeks in the greenhouse keeping distance from him. One morning, however, a previous student of the school comes to visit. We witness him caressing Äijä, stroking his cheek in a spot where the skin is softer and looser. He tells how he used to be Äijä's responsible caretaker; he still comes every now and then to see him and to check if he still remembers him. "He does." Encouraged by this, Tuure touches Äijä and strokes him, and soon I stroke it as well. (storytelling fieldnotes)

The example above illustrates how bodies and stories become ingredients of a kind of material-semiotic "compost" (Haraway, 2016). It was through listening to the stories of the lizard's former caretaker and watching him touch Äijä that we also gained the courage to touch Äijä ourselves. This event then continued to affect life in the greenhouse.

The aim of troubling the anthropocentric gaze in ethnographic work presents a vast methodological challenge. How might we justify calling our storytelling approach "multispecies"? We follow earlier multispecies ethnographic scholarship in that our ambition is not to make claims about "capturing" an authentic (animal) perspective; rather, the focus of our study is multispecies relationality, or "questions of kinds and their multiplicities" (van Dooren et al., 2016, p. 1). Animal philosopher Vinciane Despret (2016) suggests that scientists could work through creating "versions" and refers to speculative and poetic modes of knowledge, which do not need to be harmonized or coherent. One of her research protocols, "visiting," points at an approaching of the other in a polite and respectful manner, with an awareness of the possibility of mutual and intra-active shaping of the other. This kind of research can hardly be generalized or normative; rather, it is anecdotal and situated (Snaza, 2019; also Puig de la Bellacasa, 2017). Multispecies scholarship at large emphasizes the impossibility of outside observing, and instead suggests "passionate immersion" in the field (Tsing, 2010; van Dooren et al., 2016).

Most conventional qualitative research ethics are based on human individuals' integrity and safety, and they reflect the wish to control any unpredictability that might occur during the research. This wish becomes complicated in a multispecies research setting. How, for example, could you ask for informed consent from the other-than-human participants of the study? Multispecies research reveals how the formative steps of research ethics adhere to an anthropocentric worldview (Pedersen \& Pini, 2017). When a research setting is understood as a multispecies one, the ideas of individuals begin to be replaced with those of multiplicity. In these kinds of settings, participants are "always more than one" (Manning, 2013; van Dooren et al., 2016), or in fact, regarding touch, always more than two, as we are going to discuss later.

Eventually, we suggest that touching itself can be considered as a mode of multispecies methodology that involves aspects ranging from research ethics to the epistemological and ontological premises of inquiry. When we first came to the greenhouse to begin fieldwork, we went to see all the kids and their teachers, but also our other-than-human research participants. Walking around in the greenhouse from one cage to a terrarium and back, we made ourselves present to the other-than-human animals by touching the glass of terrariums, kneeling 
in front of the cages, making eye contact, noises, and movements, talking, and breathing/sniffing. Without giving it a further thought, it so happened that we touched the other-than-human animals whenever it seemed safe and appropriate (sometimes we were responded to by a bite). However, in addition to the researchers approaching the other animals, the other animals also approached the researchers. When the turtle Jimi hurried across the greenhouse floor to gnaw our leather shoes-which, according to the stories we were told, was his habit of "dancing" with his previous owner-the necessity to inquire through means other than only verbal or visual became evident.

\section{Caring hands}

A greenhouse, once established, needs daily maintenance and care. Human hands are involved in almost every aspect of organizing and taking care of this technical construction, in this case the home of many other-thanhuman animals. We followed how the children and young people moved coops and terrariums from one place to another, decorated them, wiped the floor, changed new materials for dirty ones, threw garbage away, fed the other-than-human animals, chopped food, and brought fresh water for them. Human hands were involved even in the reproductive processes of the other animals at the greenhouse (see Hohti \& Tammi, 2019). The final encounters between the hands of the caretakers and the smaller animals like gerbils had to do with death: the caring hands (the hands of one of the biology teachers) filled a glass tin with ether, dropped the gerbil in, and closed the lid tightly. This is how the smaller animals in the greenhouse were sometimes euthanized. The last time the bodies of the humans and their small companions touched each other was when the gerbils were buried or dissected during a biology lesson.

Who gets to live and die, and how, are matters of worlding (Haraway, 2008). The greenhouse world is hand led and hand dependent, shaped and conditioned throughout by the capabilities of human hands and their prostheses, such as technologies. It is along these lines that pet keeping and "animal rescue" are possible, but also uneasy questions of pain, freedom, birth, death, and killing are propelled. Of course, we do not claim that humans with hands are the only possible actants of care. However, the work of human hands in the greenhouse drew our attention because of the ways in which care and touch materialized in and through them. The capabilities of the caring hands became illuminated as noninnocent.

The material, the affective, and the ethico-political dimensions of care were also brought up by the children. At the animal club, the young leaders asked the participating children to make a list of a gerbil's daily needs on the blackboard:

Food
Water
Hay
Box
Cage
Sawdust
Tail (for balancing)
Sand
Social animal (needs other gerbils)
Seed mix
Vegetables
Berries
Insects
Stroking


The list gathers together some of the things a greenhouse gerbil is daily in touch with. Besides maintenance and provision of food, water, and a suitable environment, the children also included social and affective aspects of care in their list. But as Puig de la Bellacasa (2017) theorizes, along with the material and affective dimensions of care, the ethical and political issues emerged at once. The hay, the sawdust, the seed mix, and the cage relate to the ethically dilemmatic histories of captivity and commercial pet industry: The inherently asymmetrical power relation between humans and gerbils is the background from which the specific lives of the greenhouse gerbils emerge. The existence of an individual in isolation is rendered an illusory figuration. Be it humans or their tiny companion species gerbils, the greenhouse critters depend on assemblages of electricity, fresh water, economic resources, curricular discourses, and more.

The histories of humans and their other-than-human companions intersect in complex ways. In the course of processes of coevolution, some animal species have been bred toward the needs and desires of humans, and on the other hand, humans have become attached to and dependent on the capabilities and qualities of some otherthan-human animals: for scent, playfulness, intimacy, and so on (e.g., Haraway, 2008). How gerbils became pets is a source of stories in itself. Pet gerbils are said to descend from 20 pairs of gerbils that were captured in Mongolia in the 1950s and sent to the USA for laboratory research (New World Encyclopedia, 2019). One story about the domestication of gerbils is that they bred too rapidly, and the laboratory started giving them to the workers. Another version of the story, told to us by a pet store keeper, maintains that some workers in the laboratory understood that gerbils were sensible beings with souls and therefore started caring for them. The assemblages through which gerbils became popular pets can only be speculated on, but what is evident is that these assemblages made the gerbils "not killable" (see also Despret, 2016) but instead "strokable."

Fudge climbs on Jaana's sleeves and she takes the gerbil back onto her palms. "How did you first become interested in gerbils?" "In 2016 I was here the first time. I wondered what these are ... I was told they are gerbils. Ever since I have come to greet them every time I come here. Usually I don't take the other gerbils in my hands, just this one. This has got used to me." (storytelling fieldnotes)

Ultimately, the noninnocent shared histories of gerbils and humans have to do with bodies, hands, and rhythms. Jamie Lorimer (2007) talks about "nonhuman charisma" as a relational variable that emerges from the material and ecological properties of interacting sensory bodies. The reasons for the popularity of gerbils as pets can be found in the fact that gerbils are day-active beings, but also, their small size makes them easy for humans to accommodate, to transport, and to hold in hands. When Jaana forms a little nest with her two palms, Fudge fits into them perfectly.

\section{Stroking}

Relations of care are not only situated in time and space, but they interfere with time and create specific "care time" (Puig de la Bellacasa, 2017). Ultimately, in our study, stroking had the capacity to interfere with the temporal structuring of school. "I always come here," said one of the children. In this sense, the idea of "getting used to" hardly concerns the other-than-human animals only (see Despret, 2016). In the course of a longer period of care time, stroking can become a way of getting to know how the other is doing and what she might need.

One day Salla, one of the caretakers, approaches us with a gerbil in her palms. "Here is Musetta. It no longer does all those funny things; its ribs can be felt; its caretakers are not spending time with it." (storytelling fieldnotes)

Good care at the greenhouse included the assumption of human caretakers spending time with their "own" 
greenhouse animals in physical closeness. In the case of Jaana and several other students, this meant visiting the greenhouse before, during, and after the school day, lifting the gerbils from their terrariums, taking them into their hands, stroking, caressing, and talking to them. An intense mix of affect and care emerges along with stroking. Touch as an aspect of care has been considered as reinforcing the affective bond between individual animals and thus as elementary for the survival of the beings (Lemma, 2010). The stroking of a purring cat is one of the most rewarding experiences of cat lovers. These kinds of engagements also belong to the obvious forms of human-animal interactions that are believed to enhance the well-being of humans, which is a dominant focus of many studies on humans and their pets (e.g., Esposito et al., 2011; Prokop \& Tunnicliffe, 2010).

As Puig de la Bellacasa (2017) notes, while care is born in relationality, it also creates new relations, also surprising ones. We found one such surprise in the greenhouse when a group of boys devoted themselves to taking care of giant African snails, giving them baths and stroking them, although we had considered these creatures among the least charismatic animals in the greenhouse - their housing used to be behind the gerbils', the glass of their terrariums covered in slime.

Puig de la Bellacasa (2017) talks about "the mingling of literal and metaphorical meanings that make of touch a figure of intensified feeling, relating, and knowing" (pp. 98-99). Situated in the school environment, stroking could be simply another mode of constructing empirical species-specific knowledge about other-than-human animals. Learning to know the other as a particular significant other living in an "associated world" (Despret, 2016), however, multiplies the dimensions at hand.

\section{The precarious dance of touch}

Let us return to Jaana and Fudge and the relation between them that we have come to think of as "love at first touch." We watch the video of the small gerbil and the girl over again, mesmerized. Fudge climbs up Jaana's sleeves and she carefully takes the gerbil back onto her palms, stroking it, making sure it does not drop. However, Jaana is not holding the gerbil down, but the gerbil and the girl engage in a continuous exchange of movements and response to movements whereby a mutual balance is maintained.

"How can you tell if it likes it or how it feels about being in hands?"

"Well, at this moment it is a bit afraid."

"Do you feel it, or how do you know it?"

“Like, I don't feel it, but for so long I have only taken this gerbil ..."

“Okay. So it's different each time?”

“Yeah." (storytelling fieldnotes)

Even though the movements might seem repetitive, touch is invented differently in each repetition. In addition to larger movements, this improvisational dance includes an infinite number of smaller movements-movements so minute they are close to imperceptible. Manning (2014) draws on Gil's ideas on bodies as more than, talking about how seeming balance always requires such micro movements, as well as virtual movements: intervals, intensities, forces. She suggests that each balance is a multiplicity-there is no single axis of the body, no single point of stasis, rather only something she calls "metastability" or precarious equilibrium. For Manning, the micro movements are vibrational forces that make moving bodies multiple and complexly active. When Jaana and Fudge touch each other, they are invited into a precarious dance that demands continuous rearticulation, 
exchange, and response- a contact improvisation that is actually intra-action involving the creation of a specific spacetime. Within this field of vibrational forces consisting of smells, visions, sounds, microbes, hormones, and other chemicals, we can begin to perceive how their bodies exist beyond their skin. The human being and the gerbil as bounded individuals are not the only entities in touch here. When consisting of micro movements and in-betweens, touch is multisensory, or better: multiple.

Along with the world-making dance, a specific kind of thinking_ "thinking-with" — can emerge. The partaking entities do not necessarily merely think together, however, but the micro movements make it something like thinking from within. Following Manning (2014), this kind of thinking or knowing might feel like nonthinking. Thinking with is different than thinking about, because in it thought and movement become one in a shared dance. Such a process does not have an aim outside of itself. Rather it is a way of relating, or making space for relations, knowledges, and bodies yet to come. What emerges is not only knowledge about the other but a sort of dancing-knowing that cannot easily be put into words.

Theorizing touch and dance together suggests that where lived and fleshy relationships are at stake, neither stability nor a perfect balance can be found. There are only balancing events that render those relationships always already porous, never stable, and lively.

\section{DO NOT TOUCH}

Above, we analyzed touch as a balancing event emerging between a child body and other animal bodies. Touching events between species, those that can be likened to a dance, however, are sometimes heavily regulated. When we started our fieldwork in the greenhouse, our attention was caught by some of the notes on the walls of the terrariums and cages: "DO NOT TOUCH" or "ONLY APPOINTED ANIMAL CARERS ALLOWED TO TOUCH." Stress was an issue constantly brought up by the greenhouse kids. We were told that stress could be induced by too much stroking by too many hands-a situation very realistic, for example, during the breaks, when there often was a rush to the gerbil terrariums. While the children were expected to be in physical contact with their companion animals and were sometimes scolded by other caretakers if they had not done so, the stress discourse indicated the existing need to balance between the desire of touching and its effects.

The bunnies are sometimes so stressed. You notice it when you go to their cage and open it, they don't come to the human, for example. If you hold them on your lap, they start to nibble, and so on. (one of the student caretakers)

One of our participants, Mikael, contemplated why she had difficulty taking other animals in her hands. For her, physically touching the gerbils and stroking them were overwhelmingly uncertain acts, and the not knowing involved in them became too much. She did not want to touch the animals without being sure how they would feel about it. Touch offers us the possibility of asking and sensing what the other might be experiencing, but it also opens space for speculating what kinds of new relationalities might become produced (Puig de la Bellacasa, 2017). For Mikael, the possible consequences of touch were too precarious and uncertain, potentially exposing the participants to new vulnerabilities.

Paula is sitting with the other kids on a table, telling them about the rabbits she has at home. All the kids have gerbils in their hands. The hands do not stay still: with gerbils they have to adapt to another rhythm and movement, they become different hands, and the gerbils in turn have to adapt to another rhythm and movement with the hands ...

Now Paula holds a black gerbil so hard it can't move. It sinks its teeth into Paula's hand, biting it for a 
really long time; it did not stop for 30 seconds or so. Paula keeps yelling and screaming: "Help! help me, what can I do!" Then the gerbil finally lets go followed by a blood spill. Armi the teacher takes Paula to the water sink, cleans the wound, and puts a Band-aid on. Paula is still crying. Armi tells Paula that all the best caretakers have been bitten by their animals. Paula is not that sure: "I will never hold gerbils again, at least not black ones!" (storytelling fieldnotes)

The events storied above have provoked us to go even closer to touch, following Haraway (2016), who insists in looking at the details of a situation because they matter. As one version of touch, biting does not occur merely between two bodies: the gerbil and the child are differentially enmeshed within a larger relationality. The nose of the gerbil moves. So does the mouth of the child, and the body of the researcher is not outside of this assemblage either. This way, it is not only the skin as the boundary of distinct bodies that is involved in touching. Rather, touching emerges in between multiple moving bodies in relation.

Throughout this paper, we have used dance, specifically tango and contact improvisation, as points of reference when making sense of moving bodies in multispecies touching events. Dance helps us to understand how movement produces bodies that did not exist before. A fundamental difference, however, emerges in connection to the ethical issue of consent. The principle of mutual consent means that contact improvisation can be stopped any time. But in the interactions storied above, the possibility of escaping from the dance was not equal. Following Despret (2016), we could ask what this kind of a dance asks from us. Her approach does not try to imagine the gerbils' point of view of the dance as a truthful representation; rather, she suggests thinking with "versions" - a methodology that leads

to a multiplication of definitions and what is possible, to make more experiences visible, to cultivate equivocations, in short, to proliferate narratives that constitute us as beings who are sentient, connected with others, and affected. To translate is not to interpret, it is to experiment with equivocations. (Despret, 2016, p. 176)

Thus, we hereby offer our version. The nibbling pushes the hands-in-sensation to move differently. During the movement, or dance, biting is sometimes disciplined ("don't bite") or essentialized ("gerbils always bite"; "they bite almost everything"). Sometimes the biting pushes the humans to listen to the dance differently ("maybe it wants to go back to the terrarium") or to meet the limits of their understanding ("help, I don't understand this gerbil”). Biting, we might insist, is an example of contact improvisation gone violent. Perhaps violence was always present in the turns of the dance as a potentiality. We might also think about the shared interspecies histories in terms of dance. This way, animal captivity, commodification, and utilization for human purposes in homes, in laboratories, and in factory farming could be understood as movements on the same continuum-as violent materializations of dance. But returning to Armi's comment on the importance of bitings in learning to care, we might also consider the ways in which touching events themselves teach us abilities to respond, or response-abilities (Barad, 2007). Understood this way, care in human-animal relations cannot be standardized or taken for granted-it is relational, complex, and noninnocent.

\section{Always more than two}

In Western anthropocentric worldview there is a long tradition of thinking about relationships in terms of oneto-one interactions. As the saying goes, it takes two to tango. But as we have shown, when bodies reach out to touch each other, the consequences are never certain. With Manning (2007) we have suggested that touch cannot be separated from other sensations and movements: a body (as movement) also expands outside of its skin.

A new supply of hay had been brought in just before a winter holiday. Some students had negotiated 
with the housemaster that they could come to the greenhouse to meet the other animals despite the holidays. One day they noticed two wild mice in one of the food baskets and put them into an empty terrarium, covering it with a blanket. The plan was to keep them until spring and then release them somewhere outside of the city. A warning sign affixed to the blanket says: "DO NOT TOUCH-Risk of contamination." (storytelling fieldnotes)

By tuning to the microbial level, any wish to "know" or control touch has to be abandoned, as the number of potential participants in touch is multiplied by millions. The mice, not much different from gerbils in their physical characteristics, are "made unstrokable" due to their coexistence with potentially pathogenic microbes, such as salmonella and helicobacter. This provokes a speculation of how potentially myriads of microbial communities are in touch each time children and the other animals are (Yong, 2016). The aspect of not knowing multiplies when microbial life is given serious thought. In this sense, the greenhouse is not only a place where a multitude of animals (including humans) undergo various metamorphoses through touch inventions. To touch something or somebody means engaging in relational sensation and movement with uncertain and unforeseeable consequences. We have not heard stories about those consequences, and perhaps never will. While the majority of the existing research examines child-animal relations as one-to-one relationships and focuses on the potential benefits of those relationships for human beings, multispecies touch opens up a radical indeterminacy, one that concerns materials and bodies and numbers of bodies, but also spaces and times. Touch involves "always more than two" (Adsit-Morris \& Gough, 2017).

One of the turtles has been taken to the vet. Its shell didn't look well. The vet explains that as turtles develop new layers of shell under the old one, the old one needs to be scratched away. The turtles cannot do it themselves. We are intrigued to hear that under the layers of old and new shell there is a fungus living. Turtle shell is made of the same substances as human nails. As Satu, one of the teachers, was spreading the medicine prescribed for the turtle shell, she wondered to us whether the rash she had developed on her hands could be made by the same fungi. (storytelling fieldnotes)

Microbes help us understand the material grounds for the statement that bodies have no clear boundaries. For example, scents that are emitted due to perspiration and that add to the stress worries discussed earlier are actually metabolic products of microbes living on the skin. "Getting used to each others' smells" is an oftenrepeated imperative in the multispecies community of the greenhouse. When microbes are involved, the scale of the epistemological and methodological challenge of multispecies research starts to appear (Ogden et al., 2013; Tammi, 2019). Such research might require the ability to "zoom" into the tiny details of an event and beyond, toward speculation as a mode of inquiry (Despret, 2016; Haraway, 2016; Puig de la Bellacasa, 2017). Microbes urge us to realize that we are dealing with multiple overlapping worlds that differ from each other and that we know very little about.

\section{Touching is worlding}

The anthropocentric notion of other-than-human animals being beneficial for children is frequently brought up as if it is fact. Our own research project started from the observation that direct animal contacts are fast diminishing in Western societies, and from curiosity about the significance of animal contacts for children. However, we engaged above with touching events using theories of body, touch, and care to argue that childanimal relations are not to be simplified in this complex world. Our analyses illustrate how interspecies relationships and caring events, such as the one between Jaana and Fudge, indeed are complex because these relationships always take more than two. The specific focus on touch allows us to examine multispecies multiplicity and to observe how worlds are connected and made, including microbial ones. In addition, 
speculative worlds are involved, those created and actualizing in the very moment of touching. Human-animal relations are precarious and never certain.

When thinking about care in child-animal relations, the beautiful, affective, and productive aspects of care easily surface. The historical and cultural aspects of pet keeping involved in mundane, everyday interspecies encounters remind us that pets, as well as pedagogical and domestic animals, are often "made strokable" through situated political (colonial), economic (commercial), and technological (industrial) assemblages. Through the "desiring machine" (Pedersen, 2019) of pet keeping, unflattering histories are often inherited. The "greenhouse kids" themselves sometimes noted that the greenhouse is an artificial, technologically mediated, and politically and economically ambivalent environment: "This is not nature!"

We claim, echoing Puig de la Bellacasa (2017), that it is in this impure world that contact zones (Haraway, 2008) are formed and questions of care need to be asked. While acknowledging the urgency of the questions concerning animal captivity, commodification, treatment, and utilization, we have here presented an extension to these problematics by zooming into the details of touching events. Touching dancing events makes both humans and other animals participate in the politics of regulation and boundary making, or choreographing an "interspecies etiquette" (Warkentin, 2010). Even if this dance is likely to involve unequal power relations and destructive ideas about human exceptionalism and superiority, it also remains open and precarious, thus allowing the disruption of these very same ideas, as well as other, toxic imaginaries. In terms of education, our study perhaps opens up alternative ways of thinking about the value of children sharing their lives with other animals. Pedagogies could embrace more risky and uncertain understandings of care and touch. They could also cultivate stories that take us from "truths" toward "versions" of coexistence while embracing the noninnocent dimensions and vulnerabilities that belong therein.

Touching could be seen as a way of knowing about the other or about the world, but we suggest it is more than that. Touching is worlding, because bodies are not settled prior to their encounter. This way, touching involves both not knowing and knowing, because we can neither fully trace, follow, nor predict the worlds involved (including ourselves as parts of them). 


\section{References}

Adsit-Morris, C., \& Gough, N. (2017). It takes more than two to (multispecies) tango: Queering gender texts in environmental education. The Journal of Environmental Education, 48(1), 67-78. https://doi.org/10.1080/00958964.2016.1249330

Barad, K. (2012). On touching - The inhuman that therefore I am. differences, 23(3), 206-223. https://doi.org/10.1215/104073911892943

Blackman, L. (2012). Immaterial bodies: Affect, embodiment, mediation. SAGE.

Cutter-Mackenzie-Knowles, A., Malone, K., \& Barratt Hacking, E. (2018). Research handbook on childhoodnature: Assemblages of childhood and nature research. Springer International Handbooks of Education.

Despret, V. (2016). What would animals say if we asked the right questions? University of Minnesota Press.

Esposito, L., McCune, S., Griffin, J. A., \& Maholmes, V. (2011). Directions in human-animal interaction research: Child development, health, and therapeutic interventions. Child Development Perspectives, 5(3), 205-211. https://doi.org/10.1111/j.1750$\underline{8606.2011 .00175 . x}$

Grusin, R. (2015). The nonhuman turn. University of Minnesota Press.

Haraway, D. J. (2008). When species meet. University of Minnesota Press.

Haraway, D. J. (2016). Staying with the trouble: Making kin in the Chthulucene. Duke University Press.

Hohti, R., \& Tammi, T. (2019). The greenhouse effect: Multispecies childhood and non-innocent relations of care. Childhood, 26(2), 169-185.

Lemma, A. (2010). Under the skin: A psychoanalytic study of body modification. Routledge.

Lorimer, J. (2007). Nonhuman charisma. Environment and Planning D: Society and Space, 25, 911-932. https://doi.org/10.1068d71j

Manning, E. (2007). Politics of touch: Sense, movement, sovereignty. University of Minnesota Press.

Manning, E. (2013). Always more than one: Individuation's dance. Duke University Press.

Manning, E. (2014). Wondering the world directly-or, how movement outruns the subject. Body \& Society, 20(3-4), 162-188. https:// doi.org/10.11771357034X14546357

New World Encyclopedia. (2019). Gerbil. https://www.newworldencyclopedia.org/entry/Gerbil

Ogden, L. A., Hall, B., \& Tanita, K. (2013). Animals, plants, people, and things: A review of multispecies ethnography. Environment and Society, 4(1), 5-24. https://doi.org/10.3167/ares.2013.040102

Paxton, S. (1993). Drafting interior techniques. Contact Quarterly, 18(1), 64-78.

Pedersen, H. (2019). Schizoanalysis and animal science education. Bloomsbury.

Pedersen, H., \& Pini, B. (2017). Educational epistemologies and methods in a more-than-human world. Educational Philosophy and Theory, 49(11), 1051-1054. https://doi.org/10.1080/00131857.2016.1199925

Prokop, P., \& Tunnicliffe, S. D. (2010). Effects of having pets at home on children's attitudes toward popular and unpopular animals. Anthrozoös, 23(1), 21-35. https://doi.org/10.2752/175303710X12627079939107

Puig de la Bellacasa, M. (2017). Matters of care: Speculative ethics in more than human worlds. University of Minnesota Press.

Snaza,N.(2019).Ethologiesofeducation.CulturalStudies<->CriticalMethodologies,20(3).https://doi.org/10.11771532708619873881

Tammi, T. (2019). "What if schools were lively more-than-human agencements all along? Troubling environmental education with moldschools." Environmental Education Research. https://doi.org/10.1080/13504622.2019.1584881 
Taylor, A., \& Pacini-Ketchabaw, V. (2018). The common worlds of children and animals: Relational ethics for entangled lives. Routledge.

Tsing, A. (2010). Arts of inclusion, or, how to love a mushroom. Australian Humanities Review, 50, 191-203. http://australianhumanitiesreview.org/2011/05/01/arts-of-inclusion-or-how-to-love-a-mushroom/

Tsing, A. (2012). Unruly edges: Mushrooms as companion species. Environmental Humanities, 1(1), 141-154. https://environmentalhumanities.org/arch/vol1/EH1.9.pdf

Turner, S. (2010). Steve Paxton's “interior techniques": Contact improvisation and political power. The Drama Review, 54 (3), $123-135$. https://doi.org/10.1162/DRAM_a_00007

van Dooren, T., Kirksey, E., \& Münster, U. (2016). Multispecies studies: Cultivating arts of attentiveness. Environmental Humanities, 8(1), 1-23. https://doi.org/10.1215/22011919-3527695

Warkentin, T. (2010). Interspecies etiquette: An ethics of paying attention to animals. Ethics \& the Environment, 15(1), 101-121. https:// doi.org/10.2979/ete.2010.15.1.101

Yong, E. (2016). I contain multitudes: The microbes within us and a grander view of life. Harper Collins 